\title{
Responsabilidade social da Educação Superior: a metamorfose do discurso da UNESCO em foco ${ }^{*}$
}

Adolfo Ignacio Calderón ${ }^{1}$ Rodrigo Fornalski Pedro² Maria Caroline Vargas ${ }^{3}$

CALDERÓN, A.I.; PEDRO, R.F.; VARGAS, M.C. Social Responsibility of Higher Education: the metamorphosis of Unesco discourse in focus. Interface - Comunic., Saude, Educ., v.15, n.39, p.1185-98, out./dez. 2011.

The concept of Social Responsibility of Higher Education (SRHE) is discussed in the light of the World Conferences on Higher Education of 1998 and 2009, which were promoted by the United Nations Educational, Scientific and Cultural Organization (Unesco). In 1998, Unesco was opposed to World Bank theses and defended the State's responsibility for higher education. However, one decade later, it has incorporated and accepted neoliberal principles as valid for application to higher education. Thus, the SRHE concept has been enriched as an ethical principle that seeks to balance tensions between education as a human right and as a commercial service. While neoliberalism moves forward in the fields of hegemony and consensus, Unesco has metamorphosed to adapt to what seems to be irreversible: the victory of education as a commercial service in the molds of the World Trade Organization. A new flag has been raised: the fight against "diploma factories".

Keywords: Unesco. Higher Education. University Management. Social Responsibility. Evaluation.
Aborda-se o conceito de Responsabilidade Social da Educação Superior (RSES) à luz das Conferências Mundiais sobre a Educação Superior de 1998 e 2009, promovidas pela Organização das Nações Unidas para a Educação, a Ciência e a Cultura (Unesco). Embora, em 1998, essa organização se tenha oposto às teses do Banco Mundial, defendendo a responsabilidade do Estado pelo Ensino Superior, passada uma década, a Unesco passa a incorporar e aceitar, como válidos, princípios neoliberais aplicados à Educação Superior, valorizando o conceito de RSES enquanto princípio ético que tenta equilibrar-se na tensão entre a educação como direito humano e como serviço comercial. $\mathrm{O}$ neoliberalismo avança no campo da hegemonia, do consenso; a Unesco se metamorfoseia, adaptando-se ao que parece ser irreversível: a vitória da educação como serviço comercial no marco da Organização Mundial do Comércio, levantando, como nova bandeira, o combate às "fábricas de diplomas".

Palavras-chave: Unesco. Educação Superior. Gestão universitária. Responsabilidade social. Avaliação.
*Elaborado com base na disciplina "Tendências e

Dinâmica da Educação Superior", do Programa de Mestrado e Doutorado em Educação da Universidade Tuiuti do Paraná, e no projeto de pesquisa

"Responsabilidade social da Educação Superior: levantamento, análise e avaliação do

conhecimento acadêmico produzido no Brasil (2000-2010)", desenvolvido no Programa de Mestrado em Educação da

Pontifícia Universidade Católica de Campinas (2010, mimeo). Versão preliminar discutida durante o XV Endipe (Calderón, 2010).

${ }^{1}$ Programa de Mestrado em Educação, Pontifícia Universidade Católica de Campinas. Rod. Dom Pedro I, Km 36, Parque das Universidades. Campinas, SP, Brasil. 13.086-900. adolfo.ignacio@ puc-campinas.edu.br 2,3 Programa de Mestrado e Doutorado em

Educação, Universidade Tuiuti do Paraná. 


\section{Observação preliminar}

Durante a hegemonia do Estado de bem-estar social, a universidade legitimouse enquanto instituição monopolizadora da formação em nível superior e da investigação científica. O modelo humboldtiano tornou-se ideal a ser atingido. Com a crise desse modelo estatal e o retorno avassalador dos princípios liberais, empresários da educação, gestores e intelectuais imbuídos de uma nova visão passaram a questionar valores que sustentaram a universidade durante muitas décadas no século XX, tais como: a Educação Superior como direito social fornecido, sobretudo, pelo Estado; a Educação Superior como bem público sem fins lucrativos; e a universidade como lugar específico para a pesquisa científica.

O processo de mercantilização do Ensino Superior, e a consequente institucionalização do mercado de Ensino Superior, é um processo paulatino que tem gerado grandes resistências diante do questionamento das bases que sustentam o modelo de universidade de pesquisa (Calderón, 2000).

A universidade de pesquisa, autônoma e financiada pelo Estado, erguida e consolidada em tempos de Estado de bem-estar, mais do que questionada, está sendo destruída diante do avanço avassalador do neoliberalismo ${ }^{4} \mathrm{e}$ das políticas educacionais impulsionadas, no âmbito mundial, por grandes agências multilaterais, como é o caso do Banco Mundial, organização que se tornou um dos senhores da educação no mundo (Leher, 1999).

Por meio dos documentos elaborados durante a Conferência Mundial de Educação Superior em 1998 (Unesco, 1998a; 1998b), a Organização das Nações Unidas para a Educação, a Ciência e a Cultura (Unesco) tornou-se, na análise de importantes intelectuais (Maia, 1999; Trindade, 1999; Santos, 1998), o principal organismo internacional que fez oposição às teses do Banco Mundial, ao defender a presença e a responsabilidade do Estado pelo Ensino Superior e o acesso a ele, opondo-se a qualquer forma de mercantilização.

Passados dez anos, em 2009 foi realizada, na sede da Unesco, em Paris, uma nova Conferência Mundial de Ensino Superior que, reconhecendo a relevância dos resultados da Declaração da Conferência Mundial de Ensino Superior de 1998 (CMES-1998), aprovou o documento As novas dinâmicas do Ensino Superior e pesquisas para a mudança e o desenvolvimento social (Unesco, 2009a), estabelecendo orientações para o mundo globalizado.

O presente artigo aborda, especificamente, o conceito de responsabilidade social do Ensino Superior à luz da CMES-1998 e da Conferência Mundial sobre a Educação Superior de 2009 (CMES-2009), promovidas pela Unesco. Partindo de uma pesquisa bibliográfica, realiza uma análise comparativa entre a CMES-1998 e a CMES-2009, defendendo a tese de que, passada uma década, a Unesco passou a incorporar e aceitar, como naturalmente válidos, princípios neoliberais aplicados à educação, levantando uma nova bandeira global no campo ético-político (a luta contra as fábricas de diplomas), que se alicerça na valorização da RSES enquanto princípio ético que tenta equilibrar-se na tensão entre o liberalismo político (direitos humanos) e o liberalismo econômico (hipervalorização do mercado), metamorfoseando-se e adaptando-se ao que parece ser irreversível: a vitória da educação como serviço comercial no âmbito da Organização Mundial do Comércio.

\section{A responsabilidade social da Educação Superior no Brasil}

Tanto responsabilidade social universitária quanto responsabilidade social da Educação Superior (RSES) são termos que não possuem raízes históricas no cenário

\author{
${ }^{4}$ No presente artigo, o \\ neoliberalismo é \\ entendido na \\ perspectiva de autores \\ marxistas como Anderson \\ (1995) e Boito Júnior \\ (1999). Para o primeiro \\ autor, o neoliberalismo é \\ um fenômeno distinto \\ do simples liberalismo \\ clássico do século XIX, \\ podendo ser \\ considerado como uma \\ reação teórica e política \\ veemente contra o \\ Estado intervencionista e \\ de bem-estar social. \\ Trata-se de um ataque \\ contra qualquer limitação \\ dos mecanismos de \\ mercado por parte do \\ Estado, denunciadas com \\ uma ameaça letal à \\ liberdade, não somente \\ econômica, mas também \\ política (Anderson, \\ 1995). Para o segundo, \\ a ideologia neoliberal \\ contemporânea \\ constitui-se num \\ liberalismo econômico \\ que exalta o mercado, a \\ concorrência e a \\ liberdade da iniciativa \\ empresarial, rejeitando, \\ de modo agressivo, a \\ intervenção do Estado na \\ economia. Na ótica de \\ Boito Júnior (1999), o \\ discurso neoliberal \\ procura demonstrar a \\ superioridade do \\ mercado frente à ação \\ estatal.
}


universitário brasileiro. Quando o assunto é discutir o papel social ou a função social da universidade brasileira, o termo mais comum, historicamente cunhado, é compromisso social (Calderón, 2005).

Esse fato não significa que o termo RSES não tenha sido utilizado em outros países em contextos históricos diferentes. Lembre-se de que a universidade é uma instituição transecular (Morin, 2009) e que as discussões sobre sua função na sociedade têm sido, e ainda são, uma constante histórica nos cenários universitários locais e internacionais.

O termo RSES surgiu no Brasil basicamente com o processo de institucionalização do mercado de Educação Superior, ganhando destaque no início da primeira década do século XXI, quando instituições de Educação Superior (IES) privadas incorporaram, em suas estratégias de marketing, o discurso da responsabilidade social empresarial ou corporativa, amplamente disseminada no Brasil pelo Instituto Ethos de Empresas e Responsabilidade Social (Calderón, 2005).

Entretanto, foi precisamente ao ser incluído como uma das dez dimensões de avaliação das IES no Sistema Nacional de Avaliação da Educação Superior (Sinaes), instituído pela Lei n 10.861, de 14 de abril de 2004, e regulamentado pela Portaria $n^{\circ} 2.051$, de 9 de julho de 2004, que o termo em questão ganhou força no Brasil.

Com o Sinaes, pode-se afirmar que o que era mera tendência do mercado de Educação Superior, adotada, sobretudo, como discurso nas propagandas das IES privadas, agora assume o caráter de obrigação institucional diante da normativa estatal (Calderón, Pessanha, Soares, 2007).

Este fato gerou, inicialmente, certa confusão teórica entre o que seria a responsabilidade social da Educação Superior e a chamada extensão universitária. Trata-se de um impasse teórico que foi paulatinamente superado, na medida em que o conceito de RSES e o de compromisso social foram vinculados às discussões sobre a função social das IES. Por sua vez, a extensão universitária foi identificada como uma das três atividades universitárias, juntamente com o ensino e a pesquisa, que possibilitam que as IES cumpram sua responsabilidade social.

Existem diversos entendimentos do que seria a RSES. Trata-se de uma temática essencialmente multidisciplinar, abordada por pesquisadores e intelectuais das mais diversas áreas do conhecimento, os quais tornaram a universidade seu objeto de estudo e cenário de atuação profissional. Esses entendimentos, ora sistematizados, não são estanques e segmentados: em muitas situações, podem se entrecruzar e complementar; em outras, assumem um caráter dicotômico, mas possuem, como aspecto positivo, o didatismo implícito nas tipologias e taxonomias.

Estudos mostram a existência de vários entendimentos do que seria a RSES na realidade brasileira (Calderón, Pedro, Vargas, 2011; Calderón, 2008), que pode ser abordada como: a) tradição universitária; b) tendência do mercado; c) normatização estatal; d) estratégia de gestão das organizações; e) valores para o desenvolvimento humano; e f) projetos sociais extensionistas.

Enquanto tradição universitária, a RSES é apontada como elemento inerente à universidade, fazendo parte de suas discussões históricas no que diz respeito a sua função social.

Em sua condição de tendência do mercado, destaca-se o surgimento das discussões da RSES como reflexo da mercantilização da educação e da gestão empresarial das IES, como uma estratégia de diferenciação no mercado educacional.

Ao ser abordada como normatização estatal, ganha centralidade a dimensão jurídica da RSES, incorporada na legislação que regula o Sinaes, que tem, entre outras finalidades, a "promoção do aprofundamento dos compromissos e responsabilidades sociais das instituições de educação superior" (Brasil, 2004, p.1). Embora não exista na lei do Sinaes objetividade e clareza conceitual em torno do entendimento legal do que seria a RSES, a legislação sinaliza, como referenciais de avaliação da responsabilidade social das IES, "sua contribuição em relação à inclusão social, ao desenvolvimento econômico e social, à defesa do meio ambiente, da memória cultural, da produção artística e do patrimônio cultural" (Brasil, 2004, p.1).

No enfoque da RSES como estratégia de gestão das organizações, encontram-se tentativas de se aplicarem, nas universidades, estratégias utilizadas no âmbito da gestão empresarial, discutindo-se: 
governança institucional; instrumentos de gestão estratégica como o balanço social, estratégias de marketing, imagem organizacional, gestão sustentável e indicadores de avaliação e qualidade ${ }^{5}$.

Na perspectiva dos valores para o desenvolvimento humano, a universidade constitui um espaço irradiador de valores de cidadania, objetivando um novo padrão de desenvolvimento orientado para a sustentabilidade, valorizando-se a formação humana integral e a forma como são estruturados os projetos pedagógicos e as matrizes curriculares ${ }^{6}$.

A compreensão da RSES como projetos sociais extensionistas tem, em seu cerne, a rejeição aos projetos assistencialistas, privilegiando a contribuição da universidade para a solução dos problemas concretos da sociedade por meio de projetos de intervenção social (Silva, 2000).

A esses seis entendimentos acrescentam-se, neste artigo, mais dois que englobam visões paradigmáticas, os mesmos que apresentam matizes dicotômicas e antagônicas e permitem compreender as divergências teóricas hoje existentes: a RSES como cumprimento das atividades históricas da universidade e a RSES como resistência ao mercantilismo neoliberal.

A RSES entendida como cumprimento das atividades historicamente construídas da universidade (ensino, pesquisa e extensão universitária) diz respeito a uma visão pragmática, que, numa perspectiva weberiana, poderia ser considerada isenta de qualquer opção política ou juízo de valor, isto é, em prol ou contra a defesa dos interesses de determinados grupos sociais. Registre-se que, para Weber (1968), a tomada de posição política do pesquisador e a análise científica da política são duas coisas muito distintas. A política enquanto prática militante não se enquadra na atividade do docente-pesquisador, a ação política somente tem sentido enquanto objeto de pesquisa.

Nesta visão, a RSES restringe-se ao cumprimento da missão da universidade, que seria produzir, sistematizar e disseminar conhecimentos, por meio do ensino, da pesquisa e da extensão, com predominância das atividades de ensino sobre todas as outras. Não seria papel da universidade assumir, como bandeira, a solução ou a contribuição direta para a solução de problemas sociais, como desigualdade e injustiça social, uma vez que, como afirma Durham (2005), essas seriam finalidades do sistema educacional como um todo, e não uma atribuição da universidade. Nesta ótica, a universidade cumpriria com sua responsabilidade social na medida em que realizasse, com qualidade, as atividades de ensino, pesquisa e extensão, devendo ser este o parâmetro de avaliação.

A RSES entendida como estratégia de resistência ao mercantilismo da globalização neoliberal é uma abordagem que não discorda da tese que relaciona a RSES com a qualidade do ensino, da pesquisa e da extensão, mas vai além, ao priorizar uma explícita opção político-ideológica de resistência ao avanço do neoliberalismo. Trata-se de uma abordagem que se enquadra no paradigma do conflito, dentro de uma tradição marxista e gramsciana, que pode ser compreendida a partir do conceito de intelectual orgânico às chamadas classes populares. Como afirma Gramsci (2004, p.15):

Todo grupo social, nascendo no terreno originário de uma função essencial no mundo da produção econômica, cria para si, ao mesmo tempo, organicamente, uma ou mais camadas de intelectuais que the dão homogeneidade e consciência da própria função, não apenas no campo econômico, mas também social e político.
${ }^{5}$ Cury, Tomiello (2009); Silva (2009); Silva, Carvalho (2009); Bolan, Motta (2008); Pinto (2008); Baldissera, Noro (2007); Ashley, Ferreira, Reis (2006); Tisott (2005); Wrasse (2004).

${ }^{6}$ Haas (2009); Villar (2009); Dias Sobrinho (2008); Jimenez de la Jará, Fontecilla, Troncoso (2006); Vallaeys (2006); Juliatto (2004) 
Nesta perspectiva, tomando como referência as contribuições de Dias Sobrinho (2005), a RSES representa a função pública da Educação Superior, a qual não deve limitar-se a uma simples função instrumental de capacitação técnica e treinamento de profissionais para as empresas, devendo suas atividades possuir pertinência social, respondendo às demandas e às carências da sociedade. Na ótica desse autor, é preciso instaurar uma ética da responsabilidade social voltada ao atendimento das demandas das populações, e "não à legitimação do mercantilismo da globalização neoliberal" (Dias Sobrinho, 2005, p.171).

Desta forma, o autor defende uma postura de intransigência intelectual em relação à expansão neoliberal, que "a universidade não dê razão ao mercado, [... e que] não seja um motor da globalização da economia de mercado, mas sim da globalização da dignidade humana" (Dias Sobrinho, 2005, p.172). Tal abordagem se enquadra dentro de uma tradição de questionamento à mercantilização da Educação Superior e à privatização do público, desenvolvida por intelectuais brasileiros na década de 1990, no contexto das reformas neoliberais (Dias Sobrinho, 1999; Ristoff, 1999; Silva Junior, Sguissardi, 1999; Trindade, 1999; Catani, 1998; Fávero, 1998; Romano, 1998; Sguissardi, 1998; Cunha, 1996; Menezes, 1996; Chauí, 1995; Gentili, Silva, 1994).

\section{A responsabilidade social sob a ótica da Unesco}

Ao analisar comparativamente os documentos La enseñanza superior: las lecciones derivadas de la experiencia (Banco Mundial, 1994) e Política de mudança e desenvolvimento no Ensino Superior (Unesco, 1999), ambos publicados na primeira metade da década de 1990, Dias (2004) conclui que esses documentos representavam, na realidade, duas visões absolutamente opostas sobre a função da Educação Superior com relação à sociedade.

Para esse autor, as duas organizações partiam de diagnósticos semelhantes, mas chegavam a conclusões e propostas totalmente divergentes em relação à Educação Superior, "uns vendo-a como instrumento para reforçar o mercado, outros como uma entidade coletiva que deve ser considerada segundo suas especificidades sociais e culturais" (Dias, 2004, p.893).

Essa tendência foi reafirmada durante a Conferência Mundial sobre Educação Superior realizada em Paris, em 5 de outubro de 1998, onde se formou uma corrente que estabeleceu uma forte crítica à mercantilização do Ensino Superior, defendendo a tese da preponderância do Estado no financiamento da Educação Superior (Calderón, Pedro, Vargas, 2011).

A defesa dessa tese ganhou destaque no documento final da CMES-1998, Declaração mundial sobre a Educação Superior no século XXI: visão e ação (Unesco, 1998a, p.29), no qual constava explicitamente, como "função essencial" do Estado, o financiamento da Educação Superior.

Essa postura da Unesco era oposta à tese defendida naquela época pelo Banco Mundial, o qual pregava enfaticamente a transferência dessa responsabilidade do Estado para o setor privado, bem como: a maior diferenciação das instituições, o desenvolvimento do setor privado, a diversificação das fontes de financiamento, o pagamento de mensalidades e a prioridade aos objetivos da qualidade e equidade, entre outras bandeiras (Sguissardi, 2009; Segrera, 2009; Dias, 2004).

Deve-se registrar que a Unesco, embora defendesse a responsabilidade do Estado pela Educação Superior, não negava a importância do setor privado nem a implantação de algumas medidas de corte neoliberal, como a diversificação do sistema educacional. Ao se referir à Declaração mundial sobre Educação Superior no século XXI: visão e ação, Castanho (2000, p.166), afirmou:

$\mathrm{Na}$ verdade, trata-se de um documento de compromisso entre os modelos contemporâneos, incorporando parcialmente o modelo emergente, ou seja, o neoliberal-globalista-plurimodal, também parcialmente o modelo estabelecido e em crise de hegemonia, o democráticonacional-participativo, tendo mesmo, em certas passagens, um tom que o aproxima do referencial crítico-cultural-popular. Este último, por definição, é a voz da resistência à exclusão, da promoção da inclusão, é o discurso do não, um grito que sobe dos subterrâneos da liberdade. O modelo estabelecido e em crise de hegemonia é o discurso do talvez, que 
esconde o sim ao proclamar o não. E o modelo emergente, o neoliberal, é o discurso do sim sem disfarces, da promoção ativa da exclusão em nome da eficiência capitalista.

A análise do documento final da CMES-1998 (Unesco, 1998a) permite constatar que, ao longo dele, o termo "responsabilidade social" foi utilizado várias vezes enquanto valor importante na formação dos estudantes, educando-os para uma participação ativa na sociedade democrática, para que promovam as mudanças que propiciarão a igualdade e justiça social.

O termo RSES é utilizado nominalmente, de forma explícita, uma única vez, de forma indireta e tangencial, ao se afirmar que a gestão do Ensino Superior constitui uma responsabilidade social de primeira ordem. Vincula-se a RSES a uma estrutura gerencial que possibilite o cumprimento da missão institucional, por meio do diálogo e da participação da comunidade universitária.

Para se compreender como foi entendida a RSES na CMES-2009, tomaram-se, como referência, os resultados dessa conferência registrados no documento As novas dinâmicas do Ensino Superior e pesquisas para a mudança e o desenvolvimento social (Unesco, 2009b), elaborado tendo em consideração resultados de seis conferências regionais prévias, realizadas ao longo de 2008 em diversos pontos do planeta: Cartagena das Índias, Macau, Dakar, Nova Deli, Bucareste e Cairo (Segrera, 2010).

Ao se analisar comparativamente o documento final de uma das conferências regionais, especificamente o da Conferência Regional da Educação Superior na América Latina e no Caribe (Unesco, 2009d), realizada de 4 a 6 de junho de 2008 na cidade de Cartagena das Índias, com o documento final da CMES-2009 (Unesco, 2009b), constata-se que os referidos documentos refletem o atual cenário da Educação Superior em âmbito global, isto é, o confronto entre duas visões opostas: a Educação Superior como direito social, provida pelo Estado, versus a Educação Superior como serviço comercial, provida pelo mercado.

O documento da reunião latino-americana (Unesco, 2009d) é claramente contrastante com o documento final aprovado na CMES-2009 (Unesco, 2009b), na medida em que defende explicitamente a Educação Superior como um bem público social, um direito humano e universal, um dever do Estado, apresentando uma postura de radical rejeição às teses neoliberais.

A Educação Superior como bem público social enfrenta correntes que promovem sua mercantilização e privatização, assim como a redução do apoio e financiamento do Estado. É fundamental reverter esta tendência, de tal forma que os governos da América Latina e do Caribe garantam o financiamento adequado das instituições de Educação Superior pública e que estas respondam com uma gestão transparente [...] Afirmamos, ainda, nosso propósito de agir para que a Educação, em geral, e a Educação Superior, em particular, não sejam consideradas como serviço comercial. (Unesco, 2009d, p.3-4)

Ao se analisar o documento final da CMES-2009 (Unesco, 2009b), constata-se a hegemonia de uma visão radicalmente contrastante com a declaração regional aprovada na América Latina (Unesco, 2009d), bem como com os resultados da CMES-1998 (Unesco, 1998a), na medida em que se visualiza a incorporação e a natural aceitação de orientações neoliberais para a Educação Superior.

De acordo com Segrera (2010), durante a CMES-2009, o discurso dos participantes dos países desenvolvidos teve, em algumas situações, um acento neoliberal, diferente do discurso crítico que predominou nos participantes dos países subdesenvolvidos e em desenvolvimento. Apesar de o grupo crítico ter lutado para que, no documento final da CMES-2009, constasse que a Educação Superior é um bem público social, sendo dever dos Estados garanti-lo como prioridade das nações, após longo debate, incluiu-se a ideia da Educação Superior como bem público, e não bem público social. Contudo, deve-se destacar que, se por um lado não foi incluído o dever do Estado no seu fornecimento, por outro, não foi incluída explicitamente a Educação Superior como serviço público (Segrera, 2010).

A mudança no papel do Estado é o sinalizador principal nas mudanças discursivas da Unesco: deixou de ser sua "função essencial" o financiamento da educação (Unesco, 1998a, p.29), para limitar-se a fornecer "suporte econômico" (Unesco, 2009b, p.1). Nesse contexto, o financiamento privado deveria ser estimulado, especialmente baseado "no modelo de parceria público-privado" (Unesco, 2009b, p.6). 
${ }^{7}$ Esta orientação vai

contra as visões que

defendem que a

universidade deve

centrar-se somente na pesquisa básica,

enquanto a indústria e o mercado na pesquisa aplicada. Aponta para o equilíbrio entre pesquisa básica e aplicada, visando estimular uma sinergia entre a universidade e o mercado no âmbito do desenvolvimento tecnológico e científico.
Do documento final da CMES-2009 (Unesco, 2009b), emanam orientações para a consolidação de mercados nacionais e transnacionais de Educação Superior, tais como: a) a diversificação do sistema educacional e dos meios de seu financiamento; b) o papel central da aprendizagem a distância, por meio das novas tecnologias, a fim de atender à demanda crescente pelo Ensino Superior; c) o estímulo de sistemas de avaliação de qualidade, de credenciamento e validação de diplomas; d) a flexibilidade das pesquisas objetivando o equilíbrio entre a pesquisa básica e a pesquisa aplicada ao serviço da sociedade ${ }^{7}$; e) a procura de novos meios de expandir o campo da pesquisa e inovação por meio de parcerias públicoprivadas, de multi-stakeholders, incluindo pequenas e médias empresas.

Embora o clamor de América Latina estivesse direcionado para frear a expansão neoliberal na Educação Superior, defende-se, neste artigo, a tese de que o documento final da CMES-2009 sinaliza para a naturalização do mercado educacional, ou seja, o documento da Unesco está claramente afinado com a ideologia que aponta a concepção da Educação Superior como serviço comercial.

Nesse sentido, pode-se afirmar que a naturalização do mercado de Educação Superior, por parte da Unesco, aponta para uma identidade ou afinamento ideológico com a visão predominante, na sociedade capitalista contemporânea, nas grandes agências multilaterais e organizações intergovernamentais que orientam as políticas educacionais em âmbito planetário.

Nesta análise deve-se ressaltar que a identidade ideológica com as orientações neoliberais, consagrada no documento da CME-2009, tinha tímidos antecedentes no documento da CME-1998, que, à época, já incorporava algumas orientações, como a diversificação na Educação Superior (Castanho, 2000).

Dessa forma, constata-se que, de 1998 a 2009, a Unesco se metamorfoseia, apresentando um discurso adaptado e funcional para o que parece ser irreversível: a vitória da educação como serviço comercial no marco da Organização Mundial do Comércio.

Pode-se afirmar que essa metamorfose começa a se desenhar em documentos elaborados nos anos seguintes à CMES-1998, especificamente os documentos: Educación superior en los países en desarrollo: peligros y promesas (Banco Mundial, 2000), de autoria do Grupo Especial sobre Educação Superior e Sociedade, convocado conjuntamente pelo Banco Mundial e pela Unesco, e "Relatório sintético sobre as tendências e desenvolvimentos na educação superior desde a Conferência Mundial sobre a Educação Superior (1998-2003)", elaborado pela Unesco (2003).

Ao analisar os referidos documentos, Borges (2011) observa que a Unesco passou a assumir posicionamentos que se aproximam de uma concepção mais economicista de educação. Nesta ótica, a Educação Superior assumiria o papel de formar de acordo com as exigências do setor produtivo, as universidades assumiriam a tarefa de desenvolver a investigação aplicada, cujos resultados poderiam ser transformados em produtos passíveis de serem explorados pela indústria e outras empresas.

Segundo Borges (2011), a Unesco passou a recomendar um sistema híbrido, em que recursos privados e estatais financiassem a Educação Superior, cabendo, ao Estado, o controle e a supervisão do sistema educacional, da qualidade acadêmica das instituições, por meio da construção de um marco regulatório, da publicização dos resultados de desempenho das instituições de Educação Superior e da responsabilização daquelas que não obtivessem desempenho adequado.

Diante da constatação da naturalização das orientações neoliberais para a Educação Superior, questiona-se: se a Unesco tem-se caracterizado por apresentar bandeiras de luta e princípios ético-políticos norteadores de setores 
comprometidos com a defesa dos valores democráticos e dos interesses dos setores socialmente excluídos da sociedade global, será que também existe uma metamorfose em suas bandeiras de luta, adaptadas à nova realidade de mercado educacional naturalmente aceita na CME-2009?

A análise documental realizada no presente artigo sinaliza que também há uma mudança no âmbito das bandeiras de luta. Além de se encontrar alinhada ideologicamente com a visão da educação como serviço comercial, a Unesco, na CMES-2009, renova o discurso ético-político que detinha na CMES-1998, mantendo uma imagem progressista ao defender o combate às degree mills (Unesco, 2009a), isto é, as fábricas de diplomas - bandeira que consta explicitamente entre as recomendações feitas no "Plano de trabalho para os Estados membros da Unesco" 8 .

La educación superior transfronteriza también puede generar oportunidades para prestatarios deshonestos y de poca calidad, cuya acción debe contrarrestarse. Los proveedores espurios ("fábricas de diplomas") constituyen un grave problema. La lucha contra esas "fábricas de diplomas" exige esfuerzos multifacéticos de ámbito nacional e internacional. (Unesco, 2009c, p.5)

Se, na CMES-1998, a RSES foi abordada de forma tangencial, concebida como o cumprimento da missão institucional das IES (ensino, pesquisa e serviços comunitários), no documento final da CMES-2009 (Unesco, 2009b) ganhou papel central, na medida em que se tornou objeto do primeiro subtítulo do referido documento. Nesse subtítulo são apresentadas várias ideias que subjazem ao conceito de RSES e que complementam as ideias expostas na CMES-1998, quais sejam:

a) As instituições de Ensino Superior, por meio de suas funções principais (pesquisa, ensino e serviços comunitários), estabelecidas no contexto de autonomia institucional e de liberdade acadêmica, devem aumentar o foco interdisciplinar e promover o pensamento crítico e a cidadania ativa.

b) a RSES está diretamente relacionada com os problemas da humanidade; a Educação Superior é responsável por gerar conhecimentos que permitam sua compreensão e enfrentamento, possibilitando superar desafios mundiais, como: segurança alimentar, mudanças climáticas, uso consciente da água, diálogo intercultural, fontes de energia renovável, saúde pública, contribuindo, assim, para o desenvolvimento sustentável, a paz, o bem-estar e a realização dos direitos humanos, incluindo a igualdade entre os sexos.

c) Como parte da RSES entende-se que a instituições de Educação Superior devem também contribuir para a educação de cidadãos éticos, comprometidos com a construção da paz, com a defesa dos direitos humanos e com os valores de democracia.

Se, por um lado, mantém-se uma coerência entre os entendimentos sobre RSES que houve na CMES-1998 e na CMES-2009, por outro, pode-se afirmar que esses entendimentos ganham novos contornos dentro de um discurso que abraça os princípios neoliberais no âmbito da educação.

A RSES para os novos tempos radica na relevância e pertinência social, no cumprimento das funções universitárias diante de desafios não mais locais, mas planetários. Analisando-se o conceito de RSES no documento final da CMES-2009, verifica-se que se trata de um conceito estreitamente vinculado ao conceito de qualidade, considerada como característica primordial das IES.
${ }^{8}$ Deve-se ressaltar que, no documento original da CME-2009 (Unesco, 2009a), consta o termo "degree mills", cuja tradução mais fidedigna é "fábrica de diplomas". A versão do documento da UNESCO em espanhol (Unesco, 2009c) incorpora o espírito desse termo, ao falar de "fábricas de diplomas", diferentemente da versão em português (Unesco, 2009b), em que o sentido do termo original acaba se perdendo, na medida em que "degree mills" foi traduzido como falsificadora de diplomas, não incorporando a dimensão de fábrica, usina, isto é, a emissão em grande quantidade de diplomas de Educação Superior de cursos que podem até ter valor oficial, mas possuem reduzida aceitação no mercado por representarem cursos de baixa qualidade, prática denominada como "estelionato acadêmico" (Calderón, 2004). 
Garantia de qualidade é uma função fundamental na educação superior contemporânea e deve envolver investidores [...] Critérios de qualidade devem refletir todos os objetivos da educação superior, notavelmente o propósito de cultivar o pensamento crítico e independente nos estudantes e a capacidade de aprender por toda a vida. Eles devem estimular a inovação e a diversidade. Garantir a qualidade do ensino superior requer o reconhecimento da importância de se atrair e reter uma equipe de ensino e pesquisa comprometida, talentosa e qualificada. (Unesco, 2009b, p.3-4)

Ora, diante da recomendação da CMES-2009 de combater as "fábricas de diplomas" nos âmbitos nacional e internacional, torna-se explícita a necessidade de combater ou lutar contra as instituições que fornecem Educação Superior de forma "fraudulenta" e de "baixa qualidade", ou seja, instituições que não cumprem com sua responsabilidade social.

A interface entre o conceito de RSES e a bandeira que propõe o combate às "fábricas de diplomas" adquire complementaridade no continuum meios/objetivos ou meta/ação, na medida em que, na ótica da racionalidade instrumental weberiana, cumprir as missões institucionais com qualidade, relevância e pertinência, isto é, cumprir com RSES, seria a grande meta ou o grande objetivo; o combate às fábricas de diplomas seria o meio, a ação que possibilitaria atingir a meta/objetivo, tendo como referência "sistemas de certificação de qualidade e estruturas regulatórias" (Unesco, 2009b, p.6).

\section{Observações finais}

Embora, na CMES-2009, a Unesco tenha assumido as orientações neoliberais para a Educação Superior, deve-se destacar que seu discurso apresenta uma dimensão ética que tenta equilibrar-se entre o liberalismo econômico, hoje hegemônico no mundo, e o liberalismo político, em termos de valores democráticos de cidadania.

Nessa perspectiva, se, por um lado, aceita a diversificação das instituições de Educação Superior, estimula a iniciativa privada, retira do Estado sua função essencial no financiamento; por outro, concebe a Educação Superior, por meio da RSES, como um espaço disseminador de valores para a erradicação de problemas globais, e defende a ampliação do acesso com qualidade e com condições para que as pessoas possam concluir os estudos, opondo-se às chamadas "fábricas de diplomas", bem como, de forma contundente, às IES que não possuem, em seus objetivos, interesses públicos, ou seja, às IES voltadas somente à procura do lucro em detrimento da qualidade. Desta forma, o discurso da responsabilidade do Estado pela Educação Superior fica relegado a segundo plano, ganhando centralidade, na agenda internacional, o combate às fábricas de diplomas.

Adotando-se uma visão friedmaniana, pode-se afirmar que combater as fábricas de diplomas permite retomar as discussões em torno do papel do Estado no capitalismo competitivo, que se limitaria a regular, fiscalizar e avaliar a partir da definição dos padrões mínimos de qualidade das escolas, cabendoIhe inspecionar o cumprimento das regras do jogo, "da mesma forma que inspeciona presentemente os restaurantes para garantir a obediência a padrões sanitários mínimos" (Friedman, 1984, p.86)

Adotando-se uma visão gramsciana, pode-se afirmar que a ideologia neoliberal atua não somente no campo da coerção, por meio das agências multilaterais, mas também, e sobretudo, no campo ideológico, por meio da construção de consensos, fato este que se reflete nas mudanças ocorridas no discurso da Unesco. Este consenso nasce, segundo Gramsci (2004, p.21), do "prestígio obtido pelo grupo dominante por causa de sua posição e de sua função no mundo da produção".

Assim, por meio do consenso, cria-se a base de sustentação da nova sociedade neoliberal, que aceita e assimila as potencialidades do não-intervencionismo estatal para o florescimento dos mercados e a felicidade de todos os cidadãos (Banco Mundial, 1997).

Nesse sentido, o debate travado no âmbito global entre duas visões, isto é, a educação como serviço comercial versus a educação enquanto direito social, que tem como palco a Organização Mundial do Comércio (Borges, 2009), deixará de existir quando se construir um consenso no campo ideológico, no âmbito da sociedade civil, em relação às virtudes do liberalismo econômico para a Educação Superior. 
Contudo, neste confronto de discursos entre essas duas visões, seria ingênuo pensar que o resultado final seria um jogo de "soma zero", isto é, o trunfo do neoliberalismo e a plena mercantilização da Educação Superior a partir da consagração de um Estado mínimo.

Adotando-se uma abordagem dialética (Demo, 1995), pode-se afirmar que a "tese", isto é, a intervenção estatal na garantia da Educação Superior como direito social, ao ser negada pela sua antítese, ou seja, o discurso neoliberal, que prega a não-intervenção estatal, geraria, como síntese, a negação da negação, que acenaria para a prevalência do novo, que, neste caso, seria o modelo de universidade recomendada pela Unesco: as instituições públicas não estatais, baseadas nas parcerias público-privadas. Instituições universitárias que preservam seu caráter público, mas gerenciadas pela iniciativa privada. Instituições sem fins lucrativos, preocupadas com a qualidade e responsabilidade da Educação Superior.

\section{Colaboradores}

Adolfo Ignacio Calderón orientou a investigação, coletou dados e redigiu a versão final do artigo. Rodrigo Fornalski Pedro e Maria Caroline Vargas coletaram dados, participaram das discussões e da redação da primeira versão do artigo.

\section{Referências}

ANDERSON, P. Balanço do neoliberalismo. In: SADER, E.; GENTILI, P. (Orgs.). Pósneoliberalismo: as políticas sociais e o Estado democrático. Rio de Janeiro: Paz e Terra, 1995. p.9-23.

ASHLEY, P.; FERREIRA, R.; REIS, H. Sistema Nacional de Avaliação da Educação Superior: oportunidades para a responsabilidade social na gestão estratégica de instituições de ensino superior. Rev. Gerenc., v.5, n.1, p.23-35, 2006.

BALDISSERA, M.; NORO, G. Responsabilidade social universitária: uma ferramenta para a consolidação da imagem organizacional. In: SIMPÓSIO DE EXCELÊNCIA EM GESTÃO E TECNOLOGIA, 4., 2007, Santa Maria. Anais... Santa Maria, 2007. p.1-15.

BANCO MUNDIAL. Educación superior en los países en desarrollo: peligros y promesas. Washington: Banco Mundial, 2000.

O Estado num mundo em transformação. Washington: Banco Mundial, 1997.

. La enseñanza superior: las lecciones derivadas de la experiencia. Washington: Banco Mundial, 1994. Disponível em: <http://firgoa.usc.es/drupal/files/0101344Sp.pdf>. Acesso em: 21 jan. 2011.

BOITO JÚNIOR, A. Políticas neoliberais e sindicalismos no Brasil. São Paulo: Xamã, 1999.

BOLAN, V.; MOTTA, M. Responsabilidade social no ensino superior. Responsab. Soc., v.3, n.3, p.11-20, 2008

BORGES, M.C. A Unesco e o direito à educação superior. In: CONGRESSO IBEROAMERICANO DE POLÍTICA E ADMINISTRAÇÃO DA EDUCAÇÃO, 2., 2011, São Paulo. Anais... São Paulo, 2011. p.1-15.

A educação superior numa perspectiva comercial: a visão da Organização Mundial do Comércio. Rev. Bras. Pol. Adm. Educ., v.25, n.1, p.83-91, 2009.

BRASIL. Presidência da República. Lei no 10.861, de 14 de abril de 2004. Institui o Sistema Nacional de Avaliação da Educação Superior - SINAES e dá outras providências.

Diário Oficial da União, Brasília, DF, n.72, 15 abr. 2004. Seção 1, p.3-4. 
CALDERÓN, A.I. A responsabilidade social da educação superior: uma leitura à luz das mudanças discursivas da Unesco. In: ENDIPE - ENCONTRO NACIONAL DE DIDÁTICA E PRÁTICA DE ENSINO, 2010, Belo Horizonte. Anais... Belo Horizonte: UFMG, 2010. v.1. p.30-42.

. Responsabilidade social da educação superior: da tradição universitária à estratégia de marketing e normatização estatal. Diálogos, v.9, p.45-50, 2008. p.13-27, 2005.

Responsabilidade social: desafios à gestão universitária. Estudos, v.22, n.34, 2004.

Repensando o papel da universidade. Rev. Adm. Empres., v. 44, n.2, p.104-8,

. Universidades mercantis: a institucionalização do mercado universitário em questão. São Paulo Perspect. , v.14, n.1, p. 61-72, 2000.

CALDERÓN, A.I.; PEDRO, R.F.; VARGAS, M.C. A Unesco e a responsabilidade social da educação superior. Responsab. Soc., v.5, n.5, p.11-6, 2011.

CALDERÓN, A.I.; PESSANHA, J.; SOARES, V.L. Educação superior: construindo a extensão nas IES particulares. São Paulo: Xamã, 2007.

CASTANHO, S. A educação superior no século XXI: comentários sobre o documento da Unesco. Interface - Comunic., Saude, Educ., v.4, n.7, p.163-6, 2000.

CATANI, A.M. (Org.). Novas perspectivas nas políticas de educação superior na América Latina no limiar do século XXI. Campinas: Autores Associados, 1998.

CHAUÍ, M. Em torno da universidade de resultados e de serviços. Rev. USP, n.25, p. 5561, 1995.

CUNHA, L.A. Crise e reforma do sistema universitário. Novos Estud. CEBRAP, n.46, p.143-70, 1996.

CURY, R.; TOMIELLO, N. Sistema de logística reversa e responsabilidade social universitária: um exercício interdisciplinar. Rev. Int. Cient. Aplic., v.3, n.1, p.91-104, 2009.

DEMO, P. Metodologia científica em Ciências Sociais. São Paulo: Atlas, 1995.

DIAS, M.A.R. Dez anos de antagonismo nas políticas sobre ensino superior em nível internacional. Educ. Soc., v.25, n.88, p.893-914, 2004.

DIAS SOBRINHO, J. Avaliação da educação superior: avanços e riscos. EccoS, v.10, n.esp., p.167-93, 2008.

. Educação superior, globalização e democratização: qual universidade? Rev. Bras. Educ., v.10, n.28, p.164-73, 2005.

Avaliação e privatização do ensino superior. In: TRINDADE, H. (Org.).

Universidade em ruínas: na república dos professores. Petrópolis: Vozes, 1999. p.61-72.

DURHAM, E. A responsabilidade social das instituições de ensino superior. Estudos, v.22, n.34, p.13-27, 2005.

FÁVERO, M.L. Autonomia universitária e educação superior no Brasil. In: MOROSINI, M. (Org.). Mercosul/Mercosur: políticas e ações universitárias. Campinas: Autores Associados, 1998. p.196-204.

FRIEDMAN, M. Capitalismo e liberdade. São Paulo: Abril Cultural, 1984.

GENTILI, P.; SILVA, T.T. (Orgs.). Neoliberalismo, qualidade total e educação: visões críticas. Petrópolis: Vozes, 1994.

GRAMSCI, A. Cadernos do cárcere. Rio de Janeiro: Civilização Brasileira, 2004. v.2. 
HAAS, C.M. Responsabilidade social da educação superior: uma abordagem na perspectiva do diálogo interdisciplinar. Responsab. Soc., v.4, n.4, p.7-16, 2009.

JIMÉNEZ DE LA JARA, M.; FONTECILLA, J.M.; TRONCOSO, C.D. Responsabilidade universitária: uma experiência inovadora na América Latina. Estudos, v.24, n.36, p.5773, 2006.

JULIATTO, C.I. A responsabilidade social da universidade: uma característica e um compromisso ético da PUC-PR com a comunidade. In: COLÓQUIO INTERNACIONAL SOBRE GESTÃO UNIVERSITÁRIA NA AMÉRICA DO SUL, 4., 2004, Florianópolis.

Anais... Florianópolis, 2004. p.1-13.

LEHER, R. Um novo senhor da educação? A política educacional do Banco Mundial para a periferia do capitalismo. Outubro, v.1, n.3, p.19-30, 1999.

MAIA, A. Educação superior: perspectivas para o próximo século. In: SILVA, R. C. (Org.). Educação para o século XX: dilemas e perspectivas. Piracicaba: Editora da Unimep, 1999. p.29-38.

MENEZES, L.C. Universidade sitiada: a ameaça de liquidação da universidade brasileira. São Paulo: Perseu Abramo, 1996.

MORIN, E. Sobre a reforma universitária. In: ALMEIDA, M.C.; CARVALHO, E.A. (Orgs.). Educação e complexidade: os sete saberes e outros ensaios. São Paulo: Cortez, 2009. p.13-26.

PINTO, M.M. Responsabilidade social universitária como indicador de qualidade para o ensino superior? In: CONGRESSO NACIONAL DE EDUCAÇÃO, 8., 2008, Curitiba.

Anais... Curitiba, 2008. p.1-13.

RISTOFF, D. Boyer Commission: o modelo americano em debate. In: TRINDADE, H. (Org.). Universidade em ruínas: na república dos professores. Petrópolis: Vozes, 1999. p.61-72.

ROMANO, R. Universidade: entre as luzes e nossos dias. In: DORIA, F.A. (Org.). A crise da universidade. Rio de Janeiro: Revan, 1998. p.49-98.

SANTOS, C.R. Universidade: da crise à emancipação. In: DORIA, F.A. (Org.). A crise da universidade. Rio de Janeiro: Revan, 1998. p.95-103.

SEGRERA, F.L. Visión de la II Conferencia Mundial de Educación Superior (CMES, 2009). Acta Scient. Educ., v.32, n.1, p.105-9, 2010.

Reflexiones en torno a la financiación actual y futura de las universidades a nivel mundial. Avaliação, v.14, n.3, p.523-60, 2009.

SGUISSARDI, V. O Banco Mundial e a educação superior: revisando teses e posições? In: . (Org.). Universidade brasileira no século $X X \mathbf{X}$ : desafios do presente. São Paulo: Cortez, 2009. p.55-77.

A autonomia universitária e mudanças no ensino superior. In: CATANI, A.M. (Org.). Novas perspectivas nas políticas de educação superior na América Latina no limiar do século XXI. Campinas: Autores Associados, 1998. p. 29-48.

SILVA, C.; CARVALHO, V. A Responsabilidade social no ensino superior: da origem ao cotidiano educacional. Responsab. Soc., v.4, n.4, p.7-16, 2009.

SILVA, I.A. Responsabilidade social e sustentabilidade na universidade. A elaboração de políticas institucionais como estratégia. In: GLOBAL FÓRUM - AMERICA LATINA, 2009, Curitiba. Anais... Curitiba, 2009. p.1-7. Disponível em:<http:// www.congresso.globalforum.com.br/arquivo/2009/artigos/ E2009_T00091_PCN46495.pdf>. Acesso em: 22 jan. 2010. 
SILVA, M. Universidade e sociedade: cenários da extensão universitária. In: REUNIÃO ANUAL DA ASSOCIAÇÃO NACIONAL DE PÓS-GRADUAÇÃO E PESQUISA EM EDUCAÇÃO, 23., 2000, Caxambu. Anais... Caxambu, 2000, p.1-16. Disponível em: <http://www.anped.org.br/reunioes/23/textos/1101T.PDF>. Acesso em: 22 jan. 2010.

SILVA JÚNIOR, J.R.; SGUISSARDI, V. Novas faces da educação superior no Brasil: reforma do Estado e mudança na produção. Bragança Paulista: Editora da Universidade São Francisco, 1999.

TISOTT, S.T. Balanço social: uma experiência consolidada na FIDENE/UNIJUI. In: COLÓQUIO INTERNACIONAL DE GESTÃO UNIVERSITÁRIA DA AMÉRICA DO SUL, 5. 2005, Mar del Plata. Anais... Mar del Plata, 2005. p.1-13. Disponível em: <http:// www.inpeau.ufsc.br/wp/wp-content/BD_documentos/1679.doc >. Acesso em: 22 jan. 2010.

TRINDADE, H. Unesco e os cenários da educação superior na América Latina. In: TRINDADE, H. (Org.). Universidade em ruínas: na República dos professores. Petrópolis: Vozes, 1999. p.191-200.

UNESCO. 2009 World Conference on Higher Education: the new dynamics of higher education and research for societal change and development. Paris: Unesco, 2009a. Disponível em: <http://www.Unesco.org/fileadmin/MULTIMEDIA/HQ/ED/ED/pdf/ WCHE_2009/FINAL\% 20COMMUNIQUE\%20WCHE\% 202009.pdf>. Acesso em: 21 jan. 2011.

Conferência Mundial sobre Ensino Superior 2009: as novas dinâmicas do ensino superior e pesquisas para a mudança e o desenvolvimento social. Paris: Unesco, 2009b. Disponível em: http://aplicweb.feevale.br/site/files/documentos/pdf/ 31442.pdf. Acesso em: 21 jan. 2011.

Conferencia Mundial sobre la Educación Superior 2009: la nueva dinámica de la educación superior y la investigación para el cambio social y el desarrollo. Paris: Unesco, 2009c. Disponível em: <http://www.Unesco.org/education/WCHE2009/ comunicado_es.pdf $>$. Acesso em: 21 jan. 2011.

. Declaração da Conferência Regional da Educação Superior na América Latina e no Caribe. Avaliação, v.14, n.1, p.235-46, 2009d.

Relatório sintético sobre as tendências e desenvolvimentos na educação superior desde a Conferência Mundial sobre a Educação Superior (1998-2003). In: Educação superior: reforma, mudança e internacionalização. Brasília: Unesco Brasil, SESu, 2003. p.93-149.

Política de mudança e desenvolvimento no ensino superior. Rio de Janeiro: Garamond, 1999.

Declaración mundial sobre la educación superior en el siglo XXI: visión y acción. Paris: Unesco, 1998a. Disponível em: <http://www.Unesco.org/education/ educprog/wche/declaration_spa.htm\#marco>. Acesso em: 21 jan. 2011.

. Marco de acción prioritaria para el cambio y el desarrollo de la educación superior. Paris: Unesco, 1998b. Disponível em: <http://www.Unesco.org/education/ educprog/wche/declaration_spa.htm\#marco>. Acesso em: 21 jan. 2011.

VALLAEYS, F. O que significa responsabilidade social universitária? Estudos, v.24, n.36, p.35-56, 2006.

VILLAR, J. Responsabilidad social universitaria: nuevos paradigmas para una educación liberadora y humanizadora de las personas y las sociedades. Responsab. Soc., v.4, n.4, p.7-16, 2009. 
WEBER, M. Ciência e política: duas vocações. São Paulo: Cultrix, 1968.

WRASSE, C.L. Responsabilidade social e marketing: um estudo das instituições de ensino superior da região oeste do Paraná. 2004. Dissertação (Mestrado) - Programa de Pós-Graduação em Administração, Fundação Universidade Regional de Blumenau, Blumenau. 2004.

CALDERÓN, A.I.; PEDRO, R.F.; VARGAS, M.C. Responsabilidad social de la Educación Superior: la metamorfosis del discurso de la UNESCO en foco. Interface - Comunic., Saude, Educ., v.15, n.39, p.1185-98, out./dez. 2011.

Tráta-se del concepto de Responsabilidad Social de la Educación Superior (RSES) a la luz de las Conferencias Mundiales sobre Educación Superior de 1998 y 2009, promovidas por la Organización de las Naciones Unidas para la Educación, la Ciencia y la Cultura (Unesco). Aunque en 1998 esta organización se opuso a las tesis del Banco Mundial, defendiendo la responsabilidad estatal por la enseñanza superior, pasada una década, la Unesco incorporó y aceptó como válidos principios neoliberales en la educación superior, valorizando la RSES como principio ético que intenta equilibrarse en la tensión entre el concepto de educación como derecho humano y como servicio comercial. El neoliberalismo avanza en el campo de la hegemonía, del consenso; la Unesco se metamorfosea, adaptándose a lo que parece irreversible: la victoria de la educación como servicio comercial en la Organización Mundial del Comercio, levantando como nueva bandera el combate a las "fábricas de diplomas".

Palabras clave: Unesco. Educación Superior. Gestión Universitaria. Responsabilidad Social. Evaluación. 